\title{
Exploring International School Teachers and Professional School Staffs' Social Cognitive Career Perspective on Lifelong Career Development: A Hong Kong Study
}

\author{
Luis Miguel Dos Santos
}

Woosong Language Institute, Woosong University, Daejeon, South Korea. Email:luismigueldossantos@yahoo.com

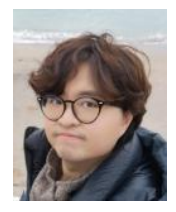

\begin{abstract}
Teaching in international schools is challenging for teachers and professional school staff due to language barriers, cultural shocks, teaching and learning expectations, support and even living standards. As a result, international schools often organise recruitment fairs to recruit professionals and prevent them from frequent departures. Such departures always cost resources and reduces the performance and morale of the schools. To understand this issue and provide a solution, the researcher collected data from 28 qualified international school teachers and professional school staff who have provided education services for more than 20 years in Hong Kong. The participants used terms such as "bridging the future leaders", "connecting both local students and international expatriates in a safe environment", "transferring foreign, home and essential knowledge to local and international students" to describe their current positions for lifelong career decisions and career development. The results of this study outlined areas on how to improve the managerial styles and teachers' professional development plans in order to retain staff population and increase the morale of incoming and junior-level teachers.
\end{abstract}

Keywords: Career decision, Career development, International school education, Teachers' professional development.

Citation | Luis Miguel Dos Santos (2020). Exploring International School Teachers and Professional School Staffs' Social Cognitive Career Perspective on Lifelong Career Development: A Hong Kong Study. Journal of Education and e-Learning Research, 7(2): 116-121.

History:

(23) January 2020

Revised: 4 March 2020

Accepted: 6 April 2020

Published: 23 April 2020

Licensed: This work is licensed under a Creative Commons

Attribution 3.0 License (oc) Er

Publisher: Asian Online Journal Publishing Group
Funding: This study is funded by Woosong Academic Research Funding 2019.

Competing Interests: The author declares that there are no conflicts of interests regarding the publication of this paper.

Transparency: The author confirms that the manuscript is an honest, accurate, and transparent account of the study was reported; that no vital accurate, and transparent account of the study was reported; that no vital
features of the study have been omitted; and that any discrepancies from the features of the study have been omit
study as planned have been explained.

Ethical: This study follows all ethical practices during writing.

\section{Contents}

1. Introduction

2. Research Design

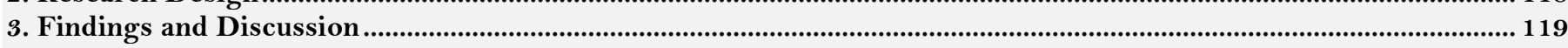

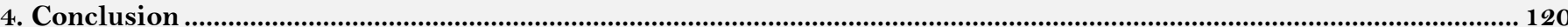

References. 


\section{Contribution of this paper to the literature}

The results of this study outlined areas on how to improve the managerial styles and teachers' professional development plans in order to retain staff population and increase the morale of incoming and junior-level teachers.

\section{Introduction}

Teaching in foreign countries and regions is one of the most popular career opportunities and developments for qualified teachers and professional school staff to start or continue their teaching professions to students with different cultural backgrounds and expectations (Dos Santos, 2019a). For nearly a century, Hong Kong has been a popular destination for international education and overseas teaching in the East Asian region due to historical, social environments and backgrounds (Bray, 2018). Besides local Chinese students from Hong Kong, international schools in Hong Kong always welcome a large number of students from different parts of the world as many expatriates, also known as expats, come to Hong Kong for career developments. As a result, there are high demands to recruit qualified teachers and professional school staff at international schools in the city and region (Odland \& Ruzicka, 2009).

Although Hong Kong is one of the most diverse cities and regions in the Far East region, most of the cultural, social, and personal expectations and practices tend to be East Asian-oriented due to the majority of Chinese population in the city. International schools are always considered as shelters for children, traditional-aged students, international teachers and professional school staff to learn the local culture and social expectations in the hosted cities and regions. Even though Hong Kong always accepts people with different types of background, teaching in international schools and learning is challenging for many teachers and professional school staff due to language barriers, cultural shocks, teaching and learning expectations, support and even living standards. Therefore, most of these educators leave their positions within the first few years of service. As a result, international schools need to organise annual recruitment fairs to recruit qualified teachers and professional school staff (Hayden \& Thompson, 2008). As much as reasonable staff turnover is positive for schools, companies and organisations, frequent departures of school professionals are costly due to the need for additional training for teachers' professional developments, adaptions, local expectations and curriculum understanding. Besides, the departures of qualified and senior-level professionals may reduce overall performances as it would be difficult to establish team morale (Ingersoll, 2001).

Some research studies (Sakurai, Parpala, Pyhältö, \& Lindblom-Ylänne, 2016) indicated that traditional-aged students usually like to acquire knowledge, practice and skills in cohort-oriented styles as teachers can track the progress and development of each student, particularly East Asian and Asian students. For example, Asian people and students tend to live in collective groups where they believe group learning is the key to children's development. Although some international schools in the Asian regions may follow westernised teaching and learning styles, curriculum and instructions, classroom management and even foreign teaching philosophy and expectation, local Asian students and even parents tend to advocate the collective teaching and learning style. For example, a study (Young, 2018) indicated that international schools in mainland China are required to teach some traditional Chinese practices, customs and skills in order to meet some of the local expectations and skills for students to survive in the Chinese society. Although many large-sized Chinese cities and metropolitans have a high degree of foreign customs and culture acceptance, non-Chinese expats still find difficulties and challenges due to some of the practical differences and understanding. Due to the differences between collectivism and individualism, some international school teachers and professional school staff may not be able to adapt to the differences between two living standards and understanding. As a result, these international school teachers and professional school staff may have a high level of burnout and stress.

\subsection{Purpose of the Study}

Based on this background, the current study aims to understand the career decisions of 28 qualified international school teachers and professional school staff who have been teaching in international schools for at least 20 years in Hong Kong. Hong Kong, one of the internationalised and globalised metropolitans located in the southern part of China as a Special Administrative Region (SAR) of China. In 1997, Hong Kong was returned from the British administration to the Chinese administration. However, due to the One Country Two System Principle, Hong Kong has maintained its living standards, ways of living, administration, and more importantly, the freedom to manage its unique educational system. Based on Hong Kong's background and its educational development, there are three purposes of this study.

First, Hong Kong as a lifelong career development destination. Unlike other international school teachers and professional school staff who usually leave their teaching positions in international environments, this study aims to understand the reasons why qualified international school teachers and professional school staff decide to stay in Hong Kong for lifelong career development. In fact, 20 years of career engagements and commitments are uncommon for international schools teachers and professional school staff with different cultural and social backgrounds. Therefore, the results of this study may provide useful information to potential readers, school leaders, international school professionals, school administrators, human resource professionals and policymakers to enhance their current human resource management plans and strategies for professional teaching recruitment in Hong Kong and other cities and regions with similar background.

Second, understanding the cultural and social expectations and background of Hong Kong from the perspective of international school teachers and professional school staff. Hong Kong is a unique city and metropolitan where East meets West. In other words, people in Hong Kong have a successful history of accepting people with different cultural and social backgrounds due to the rich historical background of the city and region. However, most of the international and local schools are suffering from a shortage of teachers, human resource problems, teachers' burnout and high teacher turnover rate (Dos Santos, 2016). It can be assumed that cultural and social background differences may be some of the challenges these international teachers and professional school staff face. Therefore, the study aims to gain understanding from some teachers and professional school staff who have invested their 
lifelong career development at international schools in Hong Kong. It is worth noting that there are some significant feedback and opinions which can be contributed to both international and local schools to enhance their teachers' professional development schemes and strategies.

Last but not least, to enhance and improve the current teachers' professional development schemes and human resources strategies based on the success stories from teachers who have invested their lifelong career development at international schools in Hong Kong.

\subsection{Theoretical Framework}

The Social Cognitive Career Theory (Lent \& Brown, 1996; Lent, Brown, \& Hackett, 1994) served as the theoretical framework to explore individuals' career decision and development which can be impacted by interests, choice of goals, performance and attainment and environmental elements. Researchers developed and enhanced the Social Cognitive Career Theory (SCCT) based on the recommendations and directions of Social Cognitive Theory by Bandura (1982) one of the leading social psychologists. SCCT also tends to understand the elements of Social Cognitive Theory and its relationships with interests, choice of goals, performance and attainment and external environmental elements. It is worth noting that individuals' behaviours are always influenced by either single or multiple factors and elements.

Both theories advocated that individuals' behaviours and actions are not the results of interactive behaviours between people and the external elements, but rather behaviours act as the interactive models which impact the results thereby impact their thinking, feelings, ideas, potential and further activities. Besides, Social Cognitive Career Theory determines the differences between intentions (people's thinking, feelings, ideas and purposes) and behaviours (the real activities and actions) as people usually believe and react to the behaviours which they believe in. Therefore, Social Cognitive Career Theory expands and extends the relationships with cultural, social, external environmental and economic factors for people's self-understanding, career development, and opportunities.

\section{Research Design}

In order to gain understanding and answers on how to enhance international school teachers and professional school staff's professional development and reduce their turnover rate in Hong Kong and similar cities and regions with similar background, the current study was guided by one research question:

1. Why do qualified international school teachers and professional school staff decide to stay in Hong Kong for lifelong career development?

\subsection{Background of the Participants}

This study reported some findings on understanding the perspectives for career decision and sense-making process of a group of qualified international school teachers and professional school staff in Hong Kong, particularly professionals who have worked in Hong Kong for at least 20 years as educators. The purposive sampling (Merriam, 2009) and phenomenological analysis (Creswell, 2012; Moustakas, 1994) were employed to collect information from 28 participants (19 Native English teachers, 2 Chemistry teachers, 2 Biology teachers, 2 Mathematics teachers and 3 counsellors) in Hong Kong. All the participants belong to three associations and groups in the city.

\subsection{Data Collection}

Based on the research question, the researcher developed two interview protocols and one focus group activity protocol in order to explore the answers. First, the researcher invited each participant to two in-depth, semistructured, one-on-one and private interview sessions with each interview lasting 120-150 minutes. Each interview session was conducted in public libraries, university libraries, community centre meeting rooms, school offices or classrooms in order to protect both the researcher and participants' privacy and confidentiality.

Second, after all the interview sessions were completed, each participant was invited to a focus group activity (14 participants to each focus group activity). As the number of participants was large, the researcher separated the participants into two groups for the focus group activity. However, the focus group activity protocols were the same as the aims and focuses were the same for both groups. Each focus group activity was hosted in a community centre meeting room for 150-187 minutes with a ten-minute break.

As for the major directions of the protocol questions, the interview protocol and focus group questions were focused on why they had decided to come to Hong Kong for their lifelong career development as international school teachers and professional school staff for more than 20 years. During the interview sessions and focus group activities, a digital recorder was used to collect all the information and sharing sessions. The data and information were digitally recorded and transcribed for validation of the content.

\subsection{Data Analysis}

The researcher first transcribed all the interview conversations and focus group activities sharing into wordbased transcripts and then thoroughly read each work multiple times. Following the steps of the general inductive approach by Thomas (2006), the transcripts were studied multiple times as prescribed by the theoretical framework.

The researcher used the open-coding strategies to narrow down the large-sized conversations and sharing sessions into first-level themes. Qualitative research (Creswell, 2012; Merriam, 2009; Tang \& Dos Santos, 2017; Thomas, 2006) advocates that qualitative research studies should be categorised into meaningful themes for reporting. Although the first-level themes contained meaningful themes, the concentrations and purposes were not significant. Therefore, the researcher further employed the axial-coding strategies to reduce the first-level themes into second-level themes for reporting. As a result, three second-level themes were defined for this study. 


\subsection{Protection of Subjects}

The protection of human subject was the most important factor in this study, particularly within the international school human resources management, international school teachers and professional school staff recruitment issues. Therefore, the researcher arranged to mask the identities of all the participants by assigning pseudonyms. The assignment of pseudonyms protects the participants so as to remain anonymous to potential employers, classmates, teachers and school administrators.

The second concern was the protection of the school sites and associations. Therefore, due to the nature of this study, the researcher did not identify any information about the schools and associations, as this was not essential.

The third concern was the storage of the collected information. For this reason, all signed agreements, records, transcripts and computer were locked in a password-protected cabinet. Only the researcher had the rights to access the cabinet. After the research had concluded, the researcher deleted and destroyed all relevant signed documents and participants' data information.

\section{Findings and Discussions}

After 56 one-on-one interview sessions and two focus group activities with the participants, the researcher eventually analysed the transcripts, data information and lived stories into meaningful themes following the general inductive approach. Through this qualitative research study, the researcher was able to conduct an inductive study of the data and build themes to answer the research question and discuss the results.

All 28 participants reported that the provision of educational services to both local and international students were significant reasons for their decisions. They mentioned the following as reasons for their lifelong career decision and development in Hong Kong for more than 20 years:

- Bridging the future leaders.

- Connecting both local students and international expatriates/students in a safe environment.

- Transferring foreign, home and essential knowledge to local and international students.

During the interviews and focus group activities, all participants indicated that teaching is not a job but a career pathway for life. They always believed that their international learning and local teaching experiences could connect with students to understand the advantages of globalisation in Hong Kong, where East meets West.

Social Cognitive Career Theory (Lent \& Brown, 1996; Lent et al., 1994) was used as the theoretical framework to study the career decision and career development of qualified international school teachers and professional school staff at international schools in Hong Kong for more than 20 years (Dos Santos, 2019a). Three major themes were categorised based on the participants' choice of goals for the students, instead of personal growth, performance, attainment and environmental elements. More importantly, all the participants expressed that they would not leave their positions as "this is a life-changing career development instead of jobs for money and financial consideration” (Participant \#28, Native English Teacher, Focus Group Activity).

\subsection{Bridging the Future Leaders}

Unlike many Chinese and East Asian people with collective living standard and style, most of the participants advocated interests and choice of goals as their major elements for staying in international schools in Hong Kong. Previous studies indicated that most young people, fresh university graduates and junior-level workers tend to select their career pathway and occupation due to external environmental factors and influences from their peers and family members (Dos Santos, 2018). However, based on the conversations and sharing sessions from these groups of participants, they focused on their goals and upper-level satisfactions. For example, 28 participants expressed the word "future leaders", "leaders of tomorrow" and "hope of the city" when describing the children and students in their classrooms and schools. It is surprising that they did not view students and parents as customers and clients but leaders of the city.

Some studies indicated that international school teachers and professional school staff leave their positions at international locations due to cultural differences and social bias. For example, a study on international school teachers and professional school staff in Fiji believed their students were too naughty to teach (Dos Santos, 2019b). Some teachers and professional school staff viewed students as customers and business clients. Therefore, their sense of teaching and providing educational services was too weak to be continued as educators at international schools (Xu, Lo, \& Wu, 2018).

In this case, all the participants did not view their students as business clients or customers but instead as future leaders of the city. During the focus group activities, all participants agreed with the word leaders as a metaphor for their students in the classroom environment. For example, a participant said, "when we view money as just a tool for teaching, we should leave this teaching profession...as this is not the way in education..." (Participant \#4, Biology, Focus Group Activity). All the other participants agreed and echoed this statement for further sharing. For example, a participant said, "children are the leaders of the future...we are here to guide them to be leaders...I want to be the lighthouse for our global community..." (Participant \#7, Native English Teacher, Focus Group Activity). It is worth noting that all participants in the focus group activities were very active in their ideas about bridging the future leaders in their classroom and school environment. More importantly, all of them advocated that money and financial considerations are not their major concerns as frontline teachers in Hong Kong. They believed that without goals and meaningful purposes in the teaching and educational profession, they would leave the city immediately and said that, "if I cannot teach these young people, I don't think I will continue my teaching career in any other place or region..." (Participant \#26, Chemistry, Interview).

In short, unlike groups such as teachers in other Asia Pacific regions (Dos Santos, 2019b), junior-level teachers who may not understand their long-term career development (Ronfeldt, Loeb, \& Wyckoff, 2013), teachers who faced cultural and social difficulties (Weiner, 2012) and teachers with conflicts from school administrators and leadership (Betoret, 2009), this group of participants understood their goals, purposes and standards of teaching at international schools in Hong Kong as international expats of the hosted city. Most believed that their personal goals, purposes and satisfactions (Lent \& Brown, 1996) always serves as their mindset for teaching. Therefore, 
school leaders and administrators should continue to build a sense of mindset and establish teachers' professional development for team building.

\subsection{Connecting Both Local Students and International Expatriates/Students in a Safe Environment}

Although all participants in this study have already invested more than 20 years of teaching in international schools in Hong Kong, a large number of participants had taught in other foreign countries or their home countries before arriving in Hong Kong. All participants advocated that students, parents, local residents, school leaders and even the Department of Education always try their best to create a safe and peaceful environment for students to learn in a classroom environment.

Although classroom safety is a compulsory requirement for many developed countries and regions internationally, a large number of teachers believed that classroom safety is not promised in many other countries and regions. For example, a participant who used to teach in France expressed that people with weapons always entered their school and playground without any notice and said, "there are guards and securities in front of the gate in Hong Kong...however, people can access any entrance in French schools... when we called the police, they [the armed people] left..." (Participant \#22, Native English Teacher, Interview).

Several others also expressed that the unique city planning and environment in Hong Kong always provided students and school staff the convenience and local access to different teaching and learning facilities and tools in the city. Due to the narrow and urban environment, students can always go to parks and other outdoor environments for science and history classes, one said, “outdoor education is unique for biology classes...we can see flowers, trees, insects...in the urban environment...Hong Kong perfectly presents the urban living cycle in our textbooks..." (Participant \#28, Biology, Interview). Furthermore, all teachers advocated that there are no kidnapping and serious crimes in Hong Kong. One participant shared his experience on outdoor mathematics lesson, said, "serious crimes are rarely found in Hong Kong...instead of indoor lessons...I like to bring my children to view some building structures for the knowledge of trigonometry..." (Participant \#15, Mathematics, Interview).

In short, providing a safe teaching and learning environment is one of the most important elements for international school teachers and professional school staff who have invested in their career development for more than 20 years in Hong Kong. Most participants advocated current social environment and safety issues for their students. In fact, many previous studies (Lenzi et al., 2017) also indicated that the safety of a city always influences the outcomes and the teaching and learning experience of students including teachers with different backgrounds (Kingston et al., 2018). It is worth noting that teachers believed and advocated that the school and government should provide safety in classrooms for their students.

\subsection{Transferring Foreign, Home and Essential Knowledge to Local and International Students}

Unlike local schools, international schools always welcome both local and international students' enrolment to those who want to experience the non-localised educational curriculum and instruction (Hardman, 2001). Previous studies (Gillies, 2001) indicated that international families and expats tend to send their children to international schools based on their nationalities, goals, university planning, financial consideration, cultural expectation and even religious factors. A number of teachers and professional school staff also indicated that transferring foreign knowledge, home educational teaching and learning experience, religious experience and even university experience during their early adulthood are some of the factors for them to stay in Hong Kong for career development (Buzan \& Gonzalez-Palaez, 2009; Hayden, 2006).

Two groups of opinions were collected. The first group of teachers expressed that they would like to transfer the educational experience, university experience, university admission procedure and living experience of their home countries and regions to their classroom students. For example, several teachers who hailed from the United Kingdom wanted to share their British university learning experience with their students said, "many of my students will eventually go back to the United Kingdom for university, I can share my experience, the UCAS procedure, and some hall experience with them...” (Participant \#4, Native English Teacher, Interview). Others who also believed that their experience can enhance the classroom experience of their students said, "some students have never been to the United Kingdom, so I can share my experience via the counselling session..." (Participant \#10, Counsellor, Interview).

Second, some teachers advocated that they needed to provide some information or guidelines about religious consideration and sense of nationality to their students. In fact, there are other international schools with different backgrounds, language of instruction and even religious background in Hong Kong (e.g. Japanese, French, German, Mandarin, Hebrew etc). Therefore, students with different nationalities, language and religious backgrounds always have different expectations of their schools, parents and teachers. Several participants who indicated that the religious perspective and knowledge are very important to their school and students said, "besides the traditional textbook knowledge, I believe religious knowledge cannot be missed out in our curriculum...children need to understand their moral practice with a religious guideline..." (Participant \#24, Counsellor, Interview).

In short, almost all participants believed that their teaching services in Hong Kong are not only for financial development but personal interests and goals (Brown \& Lent, 2017; Lent, Lopez, Lopez, \& Sheu, 2008). Many of them advocated that the unique teaching and learning experience from their home countries, regions and educational curriculum cannot be missed by their students. Also, many believed that the religious perspective and practice must be exercised even at international locations outside their home countries and region. Therefore, they believed that serving as one of the coordinators from their home countries and regions engaged them to stay in Hong Kong for more than 20 years.

\section{Conclusion}

By exploring the career decision and career development of qualified international school teachers and professional school staff who have provided educational services at international schools for more than 20 years in Hong Kong, the completion of this study will eventually contribute to the field of international education, school 
human resource management, school morale management, strategic leadership and teachers' professional development (Dos Santos, 2019b). The results of this study outlined how to improve the current managerial styles and teachers' professional development plans in order to retain staff population and increase the morale of incoming and junior-level teachers (Dos Santos, 2016). While this study focuses on Hong Kong and international schools, the study could expand in the interests of career decision and career development in other social backgrounds.

This research will continue to explore larger populations and school environments with similar backgrounds and expectations, such as mainland China, Macau, Taiwan, South Korea and Japan, who are also dealing with a shortage of qualified international school teachers and professional school staff. The study has two recommendations. First, it outlines potential elements on why this group of participants decided to invest their lifelong career development for over 20 years in Hong Kong. It helps the school leaders to improve their managerial planning for morale. Second, it allows potential qualified international school teachers and professional school staff to understand the overall background and teaching expectation in Hong Kong. The participants also indicated some difficulties due to language barriers and cultural differences. However, most of the participants believed that "meaningful teaching", "future leaders" and "bridging the future" were more important than other social bias and difficulties they faced.

\section{References}

Bandura, A. (1982). Self-efficacy mechanism in human agency. American Psychologist, 37(2), 122-147.Available at: https://doi.org/10.1037/0003-066X.37.2.122.

Betoret, F. (2009). Self-efficacy, school resources, job stressors and burnout among Spanish primary and secondary school teachers: A structural equation approach. Educational Psychology, 29(1), 45-68.Available at: https://doi.org/10.1080/01443410802459234.

Bray, M. (2018). Hong Kong education in an international context: The impact of external forces. In G. A. Postiglione \& Y. M. Leung (Eds.), Education and society in Hong Kong: Toward one country and two systems (pp. 83-97). London, UK: Routledge.

Brown, S. D., \& Lent, R. W. (2017). Social cognitive career theory in a diverse world. Journal of Career Assessment, 25(1), 173-180.Available at: https://doi.org/10.1177/1069072716660061.

Buzan, B., \& Gonzalez-Palaez, A. (2009). International society and the Middle East: English school theory at the regional level. Basingstoke, NY: Palgrave Macmillan.

Creswell, J. (2012). Qualitative inquiry and research design: Choosing among five approaches. Thousand Oaks, CA: Sage.

Dos Santos, L. M. (2016). Relationship between turnover rate and job satisfaction of foreign language teachers in Macau. Journal of Educational and Developmental Psychology, 6(2), 125.Available at: https://doi.org/10.5539/jedp.v6n2p125.

Dos Santos, L. M. (2018). Career decision of recent first-generation postsecondary graduates at a metropolitan region in Canada: A social cognitive career theory approach. Alberta Journal of Educational Research, 64(2), 141-152.

Dos Santos, L. M. (2019a). Engineering education as a second career: The experience of female practising engineers. Global Journal of Engineering Education, 21(3), 202-207.

Dos Santos, L. M. (2019b). Recruitment and retention of international school teachers in remote archipelagic countries: The Fiji experience. Education Sciences, 9(2), 132.Available at: https://doi.org/10.3390/educsci9020132.

Gillies, W. D. (2001). American international schools: Poised for the twenty-first century. Education, 122(2), 395-402.

Hardman, J. (2001). Improving recruitment and retention of quality overseas teachers. In S. Blandford \& M. Shaw (Eds.), Managing International Schools (pp. 123-135). London, UK: Routledge Falmer.

Hayden, M. (2006). Introduction to international education: International schools and their communities. London, UK: Sage.

Hayden, M., \& Thompson, J. (2008). International schools: Growth and influence. Paris, France: UNESCO.

Ingersoll, R. M. (2001). Teacher turnover and teacher shortages: An organizational analysis. American Educational Research Journal, 38(3), 499-534.Available at: https://doi.org/10.3102/00028312038003499.

Kingston, B., Mattson, S. A., Dymnicki, A., Spier, E., Fitzgerald, M., Shipman, K., \& Elliott, D. (2018). Building schools' readiness to implement a comprehensive Approach to school safety. Clinical Child and Family Psychology Review, 21(4), 433-449.Available at: https://doi.org/10.1007/s10567-018-0264-7.

Lent, R. W., \& Brown, S. D. (1996). Social cognitive approach to career development: An overview. The Career Development Quarterly, 44(4), 310-32 1.Available at: https://doi.org/10.1002/j.2161-0045.1996.tbo0448.x.

Lent, R. W., Brown, S. D., \& Hackett, G. (1994). Toward a unifying social cognitive theory of career and academic interest, choice, and performance. Journal of Vocational Behavior, 45(1), 79-122.Available at: https://doi.org/10.1006/jvbe.1994.1027.

Lent, R. W., Lopez, A. M., Lopez, F. G., \& Sheu, H. B. (2008). Social cognitive career theory and the prediction of interests and choice goals in the computing disciplines. Journal of Vocational Behavior, 73(1), 52-62.Available at: https://doi.org/10.1016/j.jvb.2008.01.002.

Lenzi, M., Sharkey, J., Furlong, M. J., Mayworm, A., Hunnicutt, K., \& Vieno, A. (2017). School sense of community, Teacher support, and students' school safety perceptions. American Journal of Community Psychology, 60(3-4), 527-537.Available at: https://doi.org/10.1002/ajcp.12174.

Merriam, S. B. (2009). Qualitative research: A guide to design and implementation. San Francisco, CA: Jossey Bass.

Moustakas, C. (1994). Phenomenological research methods. Thousand Oaks, CA: Sage.

Odland, G., \& Ruzicka, M. (2009). An investigation into teacher turnover in international schools. Journal of Research in International Education, 8(1), 5-29.Available at: https://doi.org/10.1177/1475240908100679.

Ronfeldt, M., Loeb, S., \& Wyckoff, J. (2013). How teacher turnover harms student achievement. American Educational Research Journal, 50(1), 4-36.Available at: https://doi.org/10.3102/0002831212463813.

Sakurai, Y., Parpala, A., Pyhältö, K., \& Lindblom-Ylänne, S. (2016). Engagement in learning: A comparison between Asian and European international university students. Compare: A Journal of Comparative and International Education, 46(1), 24-47.Available at: https://doi.org/10.1080/03057925.2013.866837.

Tang, K. H., \& Dos Santos, L. M. (2017). A brief discussion and application of interpretative phenomenological analysis in the field of health science and public health. International Journal of Learning and Development, 7(3), 123-132.Available at: https://doi.org/10.5296/ijld.v7i3.1 1494.

Thomas, D. R. (2006). A general inductive approach for analyzing qualitative evaluation data. American Journal of Evaluation, 27(2), 237246.Available at: https://doi.org/10.1177/1098214005283748.

Weiner, L. (2012). The future of our schools: teachers unions and social justice. Chicago, IL: Haymarket Books.

Xu, J., Lo, A., \& Wu, J. (2018). Are students customers? Tourism and hospitality students' evaluation of their higher education experience. Journal of Teaching in Travel \& Tourism, 18(3), 236-258.Available at: https://doi.org/10.1080/15313220.2018.1463587.

Young, N. A. E. (2018). Departing from the beaten path: International schools in China as a response to discrimination and academic failure in the Chinese educational system. Comparative Education, 54(2), 159-180.Available at: https://doi.org/10.1080/03050068.2017.1360566. 